\title{
On the Key Factors of Socio-Economic Policy and Institutional Development that Determine the Improvement of the Quality of Life
}

\author{
Sergey Aivazian \\ Russian Academy of Sciences, Moscow
}

\begin{abstract}
The present study is devoted to determining and assessing the relationship between the resulting (criterion) synthetic categories of the quality and way of life, on the one hand, and the direct or indirect characteristics of the current socio-economic policy and the quality of institutions, on the other hand, as well as to the analysis of the basic trends of the "Russian path" of development during the period of 1995-2004 within the "state space" of the indicators under consideration. The informational background of the study has included the data of the annual "The World Competitiveness Yearbook" during the years of 1997-2004. The study has been aimed at attempting to provide an answer to the following question: why, against the evident signs of an economic growth, Russia has not demonstrated the fundamental positive trends in the dynamics of the Quality of Life of Russian residents.
\end{abstract}

Keywords: Economic Growth, Government Policy, Russia, Econometrics.

\section{Motivation, Objectives, Tasks, and Information Base}

The analysis of dynamics (during the years of 1998-2004) of the basic indicators of the Russian economic growth, on the one hand, and of indicators of the quality of life of residents, on the other hand, has testified that against the evident signs of an economic growth, we have not, unfortunately, observed any fundamental positive trends in the key indicators of the quality of life of the Russian commonwealth. The attempt to explain the above situation has made it necessary trying to test the more general supposition, according to which: "The signs of the national economic growth are not always a sufficient factor for improving the quality of life of residents".

So, the objective of the present study is to identify the relationship between the criterion (including latent and synthetic) categories of the quality of life of the population, on the one hand, and the direct or indirect characteristics of the current socio-economic policy and the quality of institutions, on the other hand, as well as to analyze the basic trends of the "Russian path" of development during the period of 1995-2004 within the "state space" of the (criterion and explanatory) variables under consideration.

Whereas the considered explanatory variables (i.e., the characteristics of the socioeconomic policy and the quality of institutions) will include (as we will see below) the factors aimed at developing the human potential, including at improving the systems of health protection, education, and science, and ensuring the civil and political rights, the possible findings of the Study may include, for instance, a certain form of an empirical confirmation (or denial?) of the thesis on the essential instrumental role of the latter in the 
positive socio-economic development of the country, i.e., in implementing the objective of improving the QoL of the population.

To achieve the above objective of the study, the work shall solve following problems:

1. To determine the list of the resulting (criterion) synthetic categories of the quality and way of life of residents, i.e., those categories (mostly, the latent ones), which may be used as the criteria for the level of socio-economic development of the country;

2. To determine for each of the resulting (criterion) synthetic categories a specific set of the explanatory variables that shall characterize the level of the country's institutional development, as well as the adopted socio-economic policy;

3. To establish (estimate) the regression relationship between a measuring instrument for each of the resulting (criterion) category and a relevant set of the explanatory variables;

4. To analyze, basing on the data for the years of 1995-2004, the trajectories of the criterion variable and the key explanatory variables in order to identify and explain the basic trends and reveal the essential "bottle necks", i.e., the factors, the enhancement of values of which would primarily determine the further progress in the values of a measuring instrument of a relevant resulting category.

The methodology for construction the measuring instruments for the synthetic latent categories of the quality and way of life of the population described in Aivazian (2005) has been based upon the following principal concept. For each of the synthetic categories, a specific set of its partial characteristics (partial criteria) $x^{(1)}, \ldots, x^{(p)}$ capable of the direct statistical measurement has been developed. Whereupon, depending on the availability or deficiency of the expert information permitting to compare the countries within the analyzed synthetic category, a certain method of convolution of the partial criteria has been proposed, as a result of which the required integral indicator $(y)$ of the above synthetic category has been calculated as a certain function of values of the partial criteria, i.e., $y=f\left(x^{(1)}, \ldots, x^{(p)}\right)$. In other words, the partial criteria $x^{(1)}, \ldots, x^{(p)}$ playing the role of the explanatory variables generally have not been the "causes" of the result y; they have themselves been the result, appearing to be only the partial or indirect characteristics of the analyzed synthetic category.

The logic of the present study has been different. We have proceeded from the measuring instruments (i.e., the integral indicators) of the analyzed resulting (criterion) synthetic categories already been available. However, we would like to explore the way the values of the above integral indicators $y$ are subject to the explanatory variables $x^{(1)}, \ldots, x^{(p)}$, which we have assumed to include the direct or indirect characteristics of the level of the country's institutional development, as well as of the pursued socio-economic policy. In other words, the above problem statement has interpreted the explanatory variables $x^{(1)}, \ldots, x^{(p)}$ as being the causes of the analyzed results $y$, with those causes responsive in a varying degree to control and regulation. With the above logic in mind (and taking into account the options due to the available information provision) the compositions of the analyzed criterion and explanatory variables have been formed (see Sections 2 and 3 below). The Information Base of the study was formed from data of "The world Competitiveness Yearbook", Annual for 1997-2004, see WCY (1997, 1998, 1999, 2000, 2001, 2002, 2003, 2004). 


\section{The Analyzed Resulting (Criterion) Synthetic Categories of the Quality of Life of the Population}

While selecting and interpreting the resulting synthetic categories of the quality and way of life of the population, i.e., those categories (mostly, the latent ones), which may be used as the criteria of the level of socio-economic development, we shall proceed from decomposing the category "QoL of the population" in the form of a framework of the hierarchical system of statistical indicators and partial criteria proposed in Aivazian (2005), see the Fig. 1. Therethrough, we have come to the following resulting (criterion) synthetic categories of the quality and way of life and their measuring instruments:

- Quality of the population; to be measured by the "human development index", in the unit fractions (hereinafter to be designated as $\left.y^{(1)}\right){ }^{1}$

- Level of material welfare of the population; to be measured in US dollars by the "private final consumption expenditure per capita", taking into account the purchasing power parity (PPP), (hereinafter to be designated as $y^{(2)}$ );

- Quality of the social framework; to be measured according to the methods provided in the (WCY) by the expert evaluation of the "social cohesion" within a ten-point scale; (hereinafter to be designated as $y^{(3)}$ );

Lastly, the subject of the present study has also included the synthetic category of the top level of commonness:

- Quality of life of the population; to be measured according to the methods provided in the (WCY) by a relevant expert evaluation within a ten-point scale (hereinafter to be designated as $\left.y^{(4)}\right)$.

\section{An A Priori Set of the Explanatory Variables}

The main issue to be addressed within the present study has been as follows: "How do the direct or indirect characteristics of the quality of institutions and the pursued socioeconomic policy influence the values of indicators of the principal criterion categories of the quality of life of the population?"

Certainly, while forming the a priori set of the above direct or indirect characteristics (i.e., the set of the explanatory variables $\left.x^{(1)}, x^{(2)}, \ldots, x^{(p)}\right)$, we have been restricted by the scope of the information provision for the present study, specifically - the (WCY) annuals. Nonetheless, the above annuals have included the information highly valuable for solving the assigned task. According to the analysis of the data provided in the (WCY), the indicators to be nominated for inclusion into the a priori set of the explanatory variables may be arranged into the following three groups:

- Direct characteristics of the pursued socio-economic policy;

- Direct characteristics of the institutions (or the institutional development);

\footnotetext{
${ }^{1}$ The methods for calculating the value of the human development index basing on the values of: the GDP per capita, the life expectancy, the percentage of the illiterate among those aged 15 years and up and the percentage of the trainees among those aged 6 to 24 years see, for instance, in $\operatorname{HDR}(2001,2002,2003)$.
} 
- "Behavioral" and the other "partial resulting" indicators as the indirect characteristics of the quality of institutions and the pursued socio-economic policy.

The distribution of the explanatory variables selected from the $(W C Y)$ among the above groups is presented in Table 1.

The advisability of including into the a priori set of the explanatory variables "the partial resulting" indicators (including those characterizing the behavior of various strata of the population) has been based on the fact that the causes of "behavior" of each of the above characteristics could be rather easily decoded in terms of certain parameters of the pursued socio-economic policy or institutional development. Particularly, the abnormally high income differences (the variable $x^{(12)}$ ), as well as the low values of the variable $x^{(15)}$ (social responsibility of business leaders) have denoted the improper social policy and faults in resolving the legal and bureaucratic issues of business arrangement; the low values of the variables $x^{(3)}$ and $x^{(4)}$ (that shall characterize the extent of solving the pollution problems) have denoted the imperfect legislative framework in the area of environment protection etc.

While forming the a priori set of the explanatory variables, we have attempted (based on the scope of the available information provision) to represent in the above set, in particular, each of the following five types of "instrumental liberties" (see Sen, 2004) ${ }^{2}$ :

1. Political liberties: options for selecting the principles of management and the government and management bodies; possibilities for publicly controlling and criticizing the authorities; independent mass media etc.

2. Economic liberties: regulations for functioning of production and markets, options for economic exchange, benefit distribution system, availability and options for access to the finances for various economic agents etc.

3. Social options: education and health systems established by the society and the regulations for gaining an access to the society infrastructure capacities.

4. Transparency guarantees: free collaboration of members of the society under the guaranteed clarity and openness of regulations for the above collaboration and the "right for exposure".

5. Social protection: the standing institutional measures, such as the unemployment payments, material assistance to the destitute, famine relief or job creation under crisis situations etc.

\section{Identification of Analyzed Relationships}

The present section will represent the results of solving the following task. Let $y_{i}^{(j)}$ mean a value of indicator of the $j$-type resulting (criterion) synthetic category of the quality of life of the population for the $i$ country (region) $(j=1,2,3,4$, see their description in Section $2 ; i=1,2, \ldots, 46$, see the list of the analyzed countries in Table 5). And let $x_{i}^{(1)}(j), x_{i}^{(2)}(j), \ldots, x^{\left(p_{j}\right)}(j)$ mean the values of the $p_{j}$ characteristics of the a

\footnotetext{
${ }^{2}$ In accordance with the above, the instrumentality of liberties shall mean the fact that liberties may be considered as the means of achieving the desired quality of life, i.e., they contribute directly or indirectly to achieving the above objective.
} 
Table 1: Classification of the a priori-set explanatory variables.

\begin{tabular}{|c|c|c|}
\hline $\begin{array}{l}\text { Direct charac- } \\
\text { teristics of the } \\
\text { socio-economic } \\
\text { policy }\end{array}$ & $\begin{array}{l}\text { Direct charac- } \\
\text { teristics of the } \\
\text { institutional devel- } \\
\text { opment (quality of } \\
\text { institutions) }\end{array}$ & $\begin{array}{l}\text { Partial resulting indicators as the indirect char- } \\
\text { acteristics of the quality of institutions and the } \\
\text { socio-economic policy }\end{array}$ \\
\hline $\begin{array}{l}x^{(1)} \text {-total health ex- } \\
\text { penditure (percent- } \\
\text { age of GDP); } \\
x^{(5)} \text {-total public ex- } \\
\text { penditure on educa- } \\
\text { tion (percentage of } \\
\text { GDP); } \\
x^{(6)} \text {-total expendi- } \\
\text { ture on R\&D per } \\
\text { capita (annually in } \\
\text { US\$); } \\
x^{(13)} \text {-quality of pro- } \\
\text { tectionism in terms } \\
\text { of its impact on } \\
\text { business efficiency. }\end{array}$ & $\begin{array}{l}x^{(8)} \text {-quality of legal } \\
\text { regulation of finan- } \\
\text { cial institutions; } \\
x^{(9)} \text {-level of finan- } \\
\text { cial institutions' } \\
\text { transparency; } \\
x^{(10)} \text {-efficiency of } \\
\text { bureaucracy; } \\
x^{(14)} \text {-quality of jus- } \\
\text { tice }\end{array}$ & $\begin{array}{l}x^{(2)} \text {-extent of solving the problem of alcohol } \\
\text { and drug abuse; } \\
x^{(3)} \text {-extent of solving the pollution problems; } \\
x^{(4)} \text {-CO2 industrial emissions (in metric } \\
\text { tons/US\$ million of GDP); } \\
x^{(7)} \text {-level of development of basic research; } \\
x^{(11)} \text {-efficiency of solving the problem of brib- } \\
\text { ing and corruption; } \\
x^{(12)} \text {-ratio of percentage of household incomes } \\
\text { going to highest } 20 \% \text { of households and per- } \\
\text { centage of household incomes going to lowest } \\
20 \% \text { of households (income differentiation co- } \\
\text { efficient); } \\
x^{(15)} \text {-extent of social responsibility of business } \\
\text { leaders; } \\
x^{(16)} \text {-extent of ensuring the personal security } \\
\text { and private property; } \\
x^{(17)} \text {-extent of solving the problem of harass- } \\
\text { ment and violence. }\end{array}$ \\
\hline
\end{tabular}

priori set of the explanatory variables of the $j$-type criterion synthetic category for the $i$ country or region (the a priori sets of explanatory variables for each of the resulting synthetic categories are provided in the previous section). Basing on the available data: $\left(x_{i}^{(1)}(j), x_{i}^{(2)}(j), \ldots, x^{\left(p_{j}\right)}(j) ; y_{i}^{(j)}\right), i=1,2, \ldots, 46$, it shall be necessary to identify the model of relationship between $y^{(j)}$ and $x^{(1)}, x^{(2)}, \ldots, x^{\left(p_{j}\right)}$.

Prior to providing herein the results of identifying the desired relationship, we will provide only the brief comments on the process of solving of the some tasks.

\subsection{Information Provision}

Solving the tasks may be separate basing on the $W C Y$ data for each year. However, according to the special analysis, the models built on the $W C Y t_{i}$ data and the $\left(W C Y t_{j}\right)$ data $\left(t_{i}, t_{j}=1977,1988, \ldots, 2003,2004 ; t_{i} \neq t_{j}\right)$ have a statistically insignificant difference. In other words, the data obtained from the $(W C Y)$ for any two different years are, according to various known criteria, including the Chow's test, homogeneous in regression sense (see, e.g., Aivazian, 2001, Sec. 2.11). Therefore, provided below are the results of building the desired models on the most up-to-date data, i.e., exclusively the WCY (1997, 1998, 1999, 2000, 2001, 2002, 2003, 2004) data. 
Table 2: Parameters required to transform the variables that unify their measuring scales.

\begin{tabular}{|c|c|l|c|c|c|}
\hline$\#$ & Variable & & Minimum & Maximum & Optimum \\
\hline 1 & $y^{(1)}$ & $\begin{array}{l}\text { Human development index } \\
\text { (in the unit fractions) }\end{array}$ & 0 & 1 & 1 \\
\hline 2 & $y^{(2)}$ & $\begin{array}{l}\text { Final consumption of house- } \\
\text { holds per capita (in US\$) }\end{array}$ & 317 & 25548 & 25548 \\
\hline 3 & $x^{(3)}$ & $\begin{array}{l}\text { Total health expenditure } \\
\text { (percent-age of GDP) }\end{array}$ & 2.4 & 13.9 & 8.6 \\
\hline 4 & $x^{(4)}$ & CO2 emissions & 120 & 7677 & 120 \\
\hline 5 & $x^{(5)}$ & $\begin{array}{l}\text { Total public expenditure on } \\
\text { education (percentage of GDP) }\end{array}$ & 0.92 & 8.8 & 6.4 \\
\hline 6 & $x^{(6)}$ & $\begin{array}{l}\text { Total expenditure on R\&D per } \\
\text { capita (in US\$) }\end{array}$ & 0.3 & 1060 & 639 \\
\hline 7 & $x^{(12)}$ & $\begin{array}{l}\text { 20\% income differentiation } \\
\text { coefficient (in times) }\end{array}$ & 3.37 & 33.25 & 5.5 \\
\hline
\end{tabular}

\subsection{Unification of Measuring Scales of the Analyzed Variables}

As it has been noted, all the variables assessed on an expert basis are measured using a ten-point scale, where the zero points shall mean the worst situation, and 10 points - the best one. However, the variables analyzed herein have included 7 indicators measured using the other scales. The latter, according to the indexation in Sections 2 and 3, are the variables $y^{(1)}, y^{(2)}, x^{(1)}, x^{(4)}, x^{(5)}, x^{(6)}$ and $x^{(12)}$. In accordance with the recommendations in Aivazian (2005, Sec. 3.1), in order to bring the $z$ variable measured using an arbitrary scale to the above ten-point scale, it shall be necessary to apply a transformation to the above variable, i.e., to transfer to the $\tilde{z}$ variable basing on the formula:

$$
\tilde{z}=\left[1-\frac{\left|z-z_{\text {opt. }}\right|}{\max \left\{\left(z_{\text {opt. }}-z_{\min }\right),\left(z_{\max }-z_{\text {opt. }}\right)\right\}}\right] \cdot 10,
$$

where $z_{\min }, z_{\max }$, and $z_{\text {opt. }}$ are correspondingly the minimum possible, maximum possible and optimal (in the sense of a category measured by the above variable) values. The minimum, maximum and optimal values of the analyzed variables required for implementing the above transformation are provided in the Table 2.

The minimum, maximum and optimal values of the human development index $y^{(1)}$ appear from its definition (see the endnote 2). The minimum (maximum) for each of the remaining variables shall be assessed as a minimum (maximum) value of the above variable among all the 60 analyzed countries (regions). The optimum of a variable that is related to the quality by a monotone increasing (decreasing) relationship shall be assessed as its maximum (accordingly, minimum) value. Lastly, the optimal value of a variable that is related to the quality by a non-monotonic relationship (herein, these are the variables $x^{(1)}, x^{(5)}, x^{(6)}$, and $x^{(12)}$ shall be assessed as an average value of the above variable taken for the five countries that are the best under the resulting synthetic category, for which the above variable is used as an explanatory one. Herewith, if the above variable is explanatory for several resulting synthetic categories, its optimal value shall be an average of the average values calculated for the best countries under the above resulting categories. 
Table 3: The Basic Characteristics of the Analyzed Relationship

\begin{tabular}{|c|c|c|c|c|c|c|c|}
\hline \multirow[t]{2}{*}{$\tilde{y}^{(j)}$} & \multirow{2}{*}{$\begin{array}{l}\text { Relation- } \\
\text { ship }\end{array}$} & \multicolumn{5}{|c|}{ Basic explanatory variables (determinants) and their characteristics } & \multirow[t]{2}{*}{$R_{a d j}^{2}$} \\
\hline & & $\begin{array}{l}\text { Variable } \\
\text { Coefficient } \\
t \text { statistic } \\
\end{array}$ & $\begin{array}{l}\text { Intercept } \\
\hat{\theta}_{1}^{(j)} \\
t_{1}(j) \\
\end{array}$ & $\begin{array}{l}\tilde{x}^{(1)}(j) \\
\hat{\theta}_{2}^{(j)} \\
t_{2}(j) \\
\end{array}$ & $\begin{array}{l}\tilde{x}^{(2)}(j) \\
\hat{\theta}_{3}^{(j)} \\
t_{3}(j)\end{array}$ & $\begin{array}{l}\tilde{x}^{(3)}(j) \\
\hat{\theta}_{4}^{(j)} \\
t_{4}(j)\end{array}$ & \\
\hline$\tilde{y}^{(1)}$ & Linear & $\begin{array}{l}\text { Variable } \\
\text { Coefficient } \\
t \text { statistic } \\
\end{array}$ & $\begin{array}{l}\text { Intercept } \\
5.7 \\
19.2 \\
\end{array}$ & $\begin{array}{l}\text { Pollution } \tilde{x}^{(3)} \\
0.20 \\
3.5 \\
\end{array}$ & $\begin{array}{l}\mathrm{CO} 2 \tilde{x}^{(4)} \\
0.16 \\
5.1 \\
\end{array}$ & $\begin{array}{l}\text { Health } \tilde{x}^{(1)} \\
0.03 \\
2.3 \\
\end{array}$ & 0.655 \\
\hline$\tilde{y}^{(2)}$ & Power & $\begin{array}{l}\text { Variable } \\
\text { Coefficient } \\
t \text { statistic }\end{array}$ & $\begin{array}{l}\text { Intercept } \\
0.25 \\
1.3\end{array}$ & $\begin{array}{l}\text { Expenditure } \\
\text { on } \mathrm{R} \& \mathrm{D} \tilde{x}^{(6)} \\
0.60 \\
21.7\end{array}$ & $\begin{array}{l}\text { Income dif. } \\
\text { coef. } \tilde{x}^{(12)} \\
0.23 \\
2.4\end{array}$ & & 0.908 \\
\hline$\tilde{y}^{(3)}$ & Linear & $\begin{array}{l}\text { Variable } \\
\text { Coefficient } \\
t \text { statistic }\end{array}$ & $\begin{array}{l}\text { Intercept } \\
0.61 \\
1.0\end{array}$ & $\begin{array}{l}\text { Responsibility } \\
\text { of busin. } \tilde{x}^{(15)} \\
0.71 \\
5.3\end{array}$ & $\begin{array}{l}\text { Security } \\
\tilde{x}^{(16)} \\
0.26 \\
3.9\end{array}$ & & 0.627 \\
\hline$\tilde{y}^{(4)}$ & Power & $\begin{array}{l}\text { Variable } \\
\text { Coefficient } \\
t \text { statistic }\end{array}$ & $\begin{array}{l}\text { Intercept } \\
0.98 \\
13.3\end{array}$ & $\begin{array}{l}\text { Security } \tilde{x}^{(16)} \\
0.28 \\
5.0\end{array}$ & $\begin{array}{l}\text { Corruption } \\
\tilde{x}^{(11)} \\
0.23 \\
4.3\end{array}$ & $\begin{array}{l}\text { Expenditure } \\
\text { on } \mathrm{R} \& \mathrm{D} \tilde{x}^{(6)} \\
0.05 \\
3.2\end{array}$ & 0.881 \\
\hline
\end{tabular}

\subsection{Results of Identification of the Analyzed Relationships}

The basic results of calculations related to identifying the models of relationship between the indicators of the resulting (criterion) synthetic categories $y^{(y)}$ and the characteristics of the society institutional development and the pursued socio-economic policy are provided in the Table 3. The explanatory variables - determinants have been arranged within the Table for each of the resulting synthetic categories in the order of decreasing of significance of their impact on the above category that shall be determined using the relevant values of the $\hat{\theta}_{l}^{(j)}$ coefficients and their relation to the mean square error (i.e., the values of $t$-statistics).

\section{Empirical Analysis of the Relationships}

Thus, according to the results of identifying the analyzed relationship (see Table 3), only 8 out of the 17 explanatory variables of the a priori set (see Table 1) may be referred to the number of variables - determinants. The above shall include the following: personal security \& private property (variable $\tilde{x}^{(16)}$ ), extent of optimality of expenditure on R\&D $\left(\tilde{x}^{(6)}\right)$, efficiency of solving the problems of bribing and corruption $\left(\tilde{x}^{(11)}\right)$, extent of social responsibility of business leaders $\left(\tilde{x}^{(15)}\right)$, extent of solving of pollution problems $\left(\tilde{x}^{(3)}\right)$, extent of solving of problems of CO2 emissions $\left(\tilde{x}^{(4)}\right)$, extent of optimality of the level of income differentiation $\left(\tilde{x}^{(12)}\right)$, and the extent of optimality of the amount of total health 
expenditure $\left(\tilde{x}^{(1)}\right)$. At that, each of the first two variables has simultaneously been a determinant for the two resulting (criterion) categories.

Therefore, we shall analyze the "Russian path at the turn of the 21st century" within the "state space" of namely the above eight variables - determinants and surely the four analyzed resulting (criterion) synthetic categories (see Section 5.2).

\subsection{Quantitative Analysis of the Detected Regression Relationships}

Now, we shall use the results of identifying the considered models provided in the Table 3 for the purpose of their quantitative analysis.

Variation of regression values of the indicator of quality of the population $\hat{\tilde{y}}^{(1)}$ by $65.5 \%$ shall be determined by changing of the values of factors - determinants: $x^{(1)}(1)=$ $\tilde{x}^{(3)}$ (extent of solving the pollution problems), $x^{(2)}(1)=\tilde{x}^{(4)}$ (extent of solving the problem of CO2 industrial emissions), and $x^{(3)}(1)=\tilde{x}^{(1)}$ (extent of optimality of the amount of health expenditure) basing on the formula:

$$
\hat{\tilde{y}}^{(1)}=5.71+0.196 \tilde{x}^{(3)}+0.158 \tilde{x}^{(4)}+0.031 \tilde{x}^{(1)} .
$$

The above shall particularly mean that if the $\tilde{x}^{(3)}$ (or $\tilde{x}^{(4)}$, or $\tilde{x}^{(1)}$ ) assessed value is increased by $\Delta$, a value of indicator of the quality of the population will upon the average increase by $0.196 \cdot \Delta$ (correspondingly, by $0.158 \cdot \Delta$ or by $0.031 \cdot \Delta$ ). In addition, basing on the known approximation for elasticities $e_{\hat{y} / x^{(j)}}$ for the case of $\hat{y}$ linear relationship with the explanatory variables (see, e.g., Aivazian, 2001, Sec.2.9.4), it may be determined that if the $\tilde{x}^{(3)}$ (or $\tilde{x}^{(4)}$, or $\tilde{x}^{(1)}$ ) value is changed by $1 \%$, the $\hat{\tilde{y}}^{(1)}$ value will change by $0.196 \cdot \overline{\tilde{x}}^{(3)} / \bar{y}^{(1)}$ (correspondingly, by $0.153 \cdot \overline{\tilde{x}}^{(4)} / \bar{y}^{(1)}$ or by $0.031 \cdot \overline{\tilde{x}} / \bar{y}^{(1)}$ ), where $\bar{y}^{(1)}$ and $\overline{\tilde{x}}^{(j)}$ are the average values of the above indicators that are obtained as a result of averaging for all the analyzed countries.

Variation of regression values of the indicator of material welfare $\hat{\tilde{y}}^{(2)}$ by $90.8 \%$ shall be determined by changing the values of factors - determinants: $x^{(1)}(2)=\tilde{x}^{(6)}$ (extent of optimality of the amount of total expenditure on R\&D) and $x^{(2)}(2)=\tilde{x}^{(12)}$ (extent of optimality of the level of commonwealth income differentiation) basing on the formula:

$$
\hat{\tilde{y}}^{(2)}=e^{0.25} \cdot\left(\tilde{x}^{(6)}\right)^{0.6} \cdot\left(\tilde{x}^{(12)}\right)^{0.23} .
$$

The above shall particularly mean that the elasticities of $\hat{\tilde{y}}^{(2)}$ with respect to changes in $\tilde{x}^{(6)}$ and $\tilde{x}^{(12)}$ are equal to 0.6 and 0.23 correspondingly.

Variation of regression values of the indicator of social cohesion $\hat{y}^{(3)}$ by $62.7 \%$ shall be determined by changing the values of factors - determinants: $x^{(1)}(3)=x^{(15)}$ (extent of social responsibility of business leaders) and $x^{(2)}(3)=x^{(16)}$ (ensuring the personal security $\&$ private property) basing on the formula:

$$
\hat{y}^{(3)}=0.612+0.710 x^{(15)}+0.264 x^{(16)} .
$$

The above shall particularly mean that if the $x^{(15)}$ (or $x^{(16)}$ ) assessed value is increased by $\Delta$, the value of indicator of social cohesion will upon the average increase by $0.710 \cdot \Delta$ 
(correspondingly, by $0.264 \cdot \Delta$ ). The relevant elasticities $\hat{y}^{(3)}$ to $x^{(15)}$ and $x^{(16)}$ may be calculated basing on the approximations:

$$
\begin{aligned}
& e_{\hat{y}^{(3)} / x^{(15)}} \approx 0.710 \bar{x}^{(15)} / \bar{y}^{(3)} \\
& e_{\hat{y}^{(3)} / x^{(16)}} \approx 0.264 \bar{x}^{(16)} / \bar{y}^{(3)},
\end{aligned}
$$

where a fraction bar above a variable shall mean averaging of the indicator for all the analyzed countries.

Variation of regression values of the indicator of QoL of population $\hat{y}^{(4)}$ by $88.1 \%$ shall be determined by changing the values of factors - determinants: $x^{(1)}(4)=x^{(16)}$ (ensuring the personal security $\&$ private property), $x^{(2)}(4)=x^{(11)}$ (efficiency of solving the problems of bribing and corruption), and $x^{(3)}(4)=\tilde{x}^{(6)}$ (extent of optimality of the amount of expenditure on R\&D) basing on the formula:

$$
\hat{y}^{(4)}=e^{0.975} \cdot\left(x^{(16)}\right)^{0.281} \cdot\left(x^{(11)}\right)^{0.232} \cdot\left(\tilde{x}^{(6)}\right)^{0.049} .
$$

The above shall particularly mean that the elasticities of $\hat{y}^{(4)}$ with respect to changes in $x^{(16)}, x^{(11)}$, and $\tilde{x}^{(6)}$ are equal to $0.281,0.232$, and 0.049 , correspondingly.

\subsection{Analysis of Dynamics of the Path of Russian Resulting Synthetic Categories and their Determinants}

Now, we have furnished the $y^{(1)}, \ldots, y^{(4)}$ indicators and $x^{(j)}, j=1,3,4,6,11,12,15,16$, determinants with the second $t$ inferior index, so that $y_{i t}^{(l)}$ and $x_{i t}^{(j)}$ are the values of, correspondingly, the indicator of the $l$ resulting synthetic category and the $j$ determinant that have been registered for the $i$ country in a $t$ year $(t=1995,1996, \ldots, 2004)$. When speaking about the dynamics analysis, in accordance with Aivazian (2005), we shall distinguish between an autodynamics (when they monitor changing of the $y_{i t}^{(l)}$ and $x_{i t}^{(j)}$ values of the considered indicator, which shall characterize one of the countries in different years) and a place-to-place dynamics (when they monitor changing of a country's position among the other countries). To measure the Russia's place-to-place dynamics, we shall orient ourselves towards the dynamics of Russia's position (of the $t_{t}\left(y^{(l)}\right)$ or $t_{t}\left(x^{(j)}\right)$ rank) in a row of the analyzed countries according to the resulting synthetic category $y^{(l)}$ or the value of the $x^{(j)}$ determinant. The autodynamics and place-to-place dynamics of the analyzed resulting synthetic categories and their determinants for Russia basing on the WCY (1997, 1998, 1999, 2000, 2001, 2002, 2003, 2004) data are provided in Table 4. Herewith, an upper number in each line shall provide a numerical value of a variable, and a lower number (below a slant line) - the rank (i.e., the ordinal position) of Russia for the above indicator among the 46 analyzed countries. Values of all the variables are provided using a ten-point scale (the empty cells are due to the absence of required data).

Human development index path $\tilde{y}_{t}^{(1)}$ and its determinant. Expectedly (based on its definition), the above synthetic category is the most inertial and most variable. Here, Russia has unalterably been ahead of only six of the 46 compared countries: India, Indonesia, China, Philippines, the South African Republic, and Turkey, i.e., the countries with the lowest indicators of life expectancy at birth. Only within one of the components used for 
calculating the $y^{(1)}$ value, Russia has so far had the steady worthy positions - the percentage of the literate. Namely the above indicator has kept Russia out of descending to the very bottom of the list of countries compared in $T y^{(1)}$. Within another key component life expectancy at birth, Russia has been an obvious outsider. According to the obtained relationship, the main reserve in improving the situation is the radical improvement of the environmental protection policy, i.e., upgrading the extremely low (see Table 4) values of the determinants $x^{(3)}$ and $\tilde{x}^{(4)}$. Reserves of the third determinant - optimality of health expenditure $\tilde{x}^{(1)}$ - have also been used very scantily, as judged by its very modest assessed values (see Table 4).

Path of the indicator of the level of material welfare of the Russian population $\tilde{y}_{t}^{(2)}$ and its determinants. Analysis of the $\tilde{y}_{t}^{(2)}$ path (see the relevant line in Table 4) has denoted the Russia's stable outsider positions under the above indicator. Despite the outlined (since the year of 2000) distinct trend towards a certain growth of the original $\tilde{y}_{t}^{(2)}$ variable, Russia has continued to occupy the 42nd place (out of the 46) being only ahead of India, China, Philippines and Indonesia and falling behind all the other countries, including such South American countries as Columbia, Argentina, Brazil and Venezuela, all East European countries etc. According to the derived relationship, the $\tilde{y}^{(2)}$ growth reserves shall primarily be sought in developing the economy of knowledges (represented by the expenditure of R\&D) and in measures for reducing the commonwealth income differences (i.e., increasing the $\tilde{x}^{(12)}$ value). Within the above two variables (i.e., $\tilde{x}^{(6)}$ and $\tilde{x}^{(12)}$ ), Russia has steadily taken the "close-to-outsider" positions (within $\tilde{x}^{(6)}$ - between the 33rd and 39th places, and within $\tilde{x}^{(12)}$ - between the 37th and 40th places) and has demonstrated no positive trends during 1995-2002 (see Table 4).

Path of the level of social cohesion in the Russian society $y_{t}^{(3)}$ and its determinants. Here, Russia has again been an outsider (between the 41st and the last 46th places, see Table 4), and again, only a feeble trace of a positive trend has been registered (the last place in 1999 was followed by the 43rd place in 2003 and 2004; Russia was only ahead of Venezuela, Poland and Argentina or Italy, depending on a specific year). The two determinants have by $62.7 \%$ accounted for fluctuation of the above synthetic category (see Table 3 ): the extent of social responsibility of business leaders (variable $\tilde{x}^{(15)}$ ) and extent of ensuring personal security and private property (variable $\tilde{x}^{(16)}$ ). The above determinants are "behavioral" in their nature (see Table 3), however, management specialists are quite able to identify those urgent (and realistic!) improvements of the Russian institutions and the pursued socio-economic policy that may notably increase the values of $\tilde{x}^{(15)}$ and $\tilde{x}^{(16)}$ variables. Meanwhile, within the above two variables, Russia has taken the 2nd-3rd and 2nd-5th places from the end of the list, correspondingly: in 2004, the social responsibility of business leaders was worse only in Argentina and Poland, and ensuring the personal security and private property - in Argentina, Venezuela, Poland and Mexico.

Path of the synthetic category "quality of life of the Russian population" and its determinant. To put it mildly, the Russian path of the QoL synthetic category itself has offered no hopes (see Table 4): Russia's last place in 1997-2000 was followed by the next-tolast place in 2001-2003, and in 2004, Russia managed to get ahead of the two countries within the above indicator (Venezuela and Argentina). However, analysis of the analyzed relationship has allowed to lay down the ways for upgrading the QoL level based on improving the socio-economic policy and institutional development. Indeed, according to 
the this relationship and Table 3, the QoL level shall by $88.1 \%$ be determined by the ability of the state and community to ensure the personal security and private property (the $x^{(16)}$ variable), to lower the level of bribing and corruption (the $x^{(11)}$ variable) and to provide a sufficient impetus for developing the economy of knowledges (the $\tilde{x}^{(6)}$ variable)! Herewith, the quantitative analysis using the elasticities $\hat{y}^{(4)}$ to $x^{(16)}, x^{(11)}$, and $x^{(6)}$ and the standard procedures for assessing on an expert basis the $y^{(4)}, x^{(16)}$, and $x^{(11)}$ values has allowed to obtain a relationship of an "expenditure - result" type that has determined the efficiency of institutional or political reforms aimed at increasing the values of the $x^{(16)}, x^{(11)}$, and $x^{(6)}$ determinants in order to improve the quality of life.

\section{Conclusions}

The results of calculations have explained why even against the (fragmentally) positive dynamics of Russian economy (rather decent indicators of general economic growth, well-doing in the part of export and gold and foreign exchange reserves) the key resulting indicators of the quality and way of life of Russian population have remained at an extremely low level and have had no significant positive dynamics. Also, the above results have revealed (not at the belletristic, but at the quantitative level) those key categories of improving the Russian institutions and socio-economic policy, under which it shall primarily be necessary to obtain success in improving the quality of life of commonwealth.

In particular, results of the econometric analysis of the relationships under examination (see Table 3) have allowed making the following conclusions.

1) One of the major characteristics of the economy of knowledges - expenditure on scientific \& research and development works (variable $x^{(6)}$ ) - has played the role of a determinant (with very high indicators of specific significance - values of the $t$ statistic!) both as an explanatory variable of the level of material welfare $\tilde{y}^{(2)}$ and as an explanatory variable of the quality of life of commonwealth $y^{(4)}$. The above has statistically proved the available historical examples (see paragraph 1 above) that indicated at the antecedence of the factor of economy of knowledges in its causal relation with the quality of life of commonwealth. Conclusion: the priority development of economy of knowledges and, in particular, a significant increase of expenditure on $R \& D$ shall be recognized as an efficient means of improving the quality of life of Russian population.

2) Society member (physical) security and private property (institutional) security (variable $x^{(16)}$ ) have, similarly to the expenditure on R\&D (variable $x^{(6)}$ ), twice played the role of a determinant within the relationships under examination: the above security has been a significant explanatory factor both for the level of social cohesion $y^{(3)}$ and for the quality of life of commonwealth $y^{(4)}$ ! Conclusion: it shall be necessary to promptly admit the required emphasis within the pursued socio-economic policy and measures for improving the country institutional development, which is aimed at ensuring a significantly higher level of physical security of members of the society and strengthening the private property institution.

3 ) The presence of the following variables: $\tilde{x}^{(1)}$ (total health expenditure), $\tilde{x}^{(3)}$ (extent of solving the pollution problems), $\tilde{x}^{(4)}$ (CO2 industrial emissions), $\tilde{x}^{(12)}$ (characteristics of population income differentiation), $\tilde{x}^{(11)}$ (level of bribing and corruption), and $\tilde{x}^{(15)}$ 
(extent of social responsibility of business leaders) among the factors - determinants that have had a decisive impact on the values of criterion indicators of the quality and way of life has necessitated the institutional reforming in the area of socio-economic policy aimed at substantially improving the situation with environment pollution, reducing the level of bribing and the commonwealth income difference level, as well as increasing the social responsibility of business leaders.

\section{Acknowledgements}

This work was supported by the Russian Foundation for Humanitarian Investigations (Projects \# 05-02-02189 a and 05-02-12211 b), and by the Russian Foundation for Basic Investigations (Projects \# 07-07-00219 and 07-06-00181).

\section{References}

Aivazian, S. A. (2001). Essentials of Econometrics. Moscow: Unity.

Aivazian, S. A. (2005). Synthetic indicators of quality of life: Construction and utilization for social-economic management and comparativ analysis. Austrian Journal of Statistics, 34, 69-77.

HDR. (2001, 2002, 2003). Human development report. New York: United Nations Development Program.

Sen, A. (2004). Development as Freedom. New York: Alfred A. Knopf.

WCY. (1997, 1998, 1999, 2000, 2001, 2002, 2003, 2004). The world competitiveness yearbook/ edition imd. Lausanne, Switzerland: International.

Author's Address:

Sergey Aivazian

Central Economics and Mathematics Institute

Russian Academy of Sciences

Nakhimovskiy Avenue, 47

117418 Moscow

Russia

E-mail: aivazian@cemi.rssi.ru 


\begin{tabular}{|c|c|c|c|c|c|c|c|c|c|c|c|c|}
\hline$\underset{\overbrace{}}{\mathbb{N}}$ & 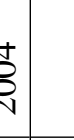 & & 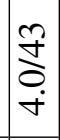 & 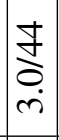 & & $\begin{array}{l}\hat{n} \\
\infty \\
\dot{\gamma}\end{array}$ & & & 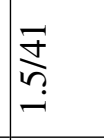 & & $\begin{array}{l}\frac{J}{5} \\
\stackrel{n}{n} \\
\dot{n}\end{array}$ & 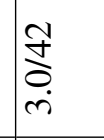 \\
\hline z & & $\stackrel{\mathcal{I}}{\mathcal{I}}$ & $\begin{array}{l}\stackrel{n}{+} \\
\dot{\sigma} \\
\dot{r}\end{array}$ & $\begin{array}{l}\mathfrak{n} \\
\stackrel{+}{+} \\
\end{array}$ & & $\frac{\stackrel{\rho}{m}}{m}$ & & & 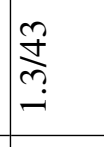 & & $\begin{array}{l}\stackrel{n}{f} \\
\stackrel{\partial}{0} \\
\dot{m}\end{array}$ & 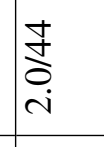 \\
\hline 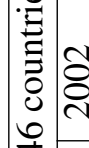 & & 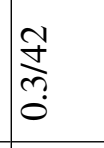 & 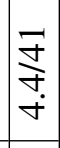 & $\begin{array}{l}n \\
\tilde{+} \\
\sim \\
\sim\end{array}$ & & 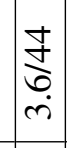 & & $\frac{n}{n}$ & 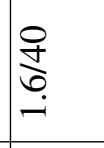 & & 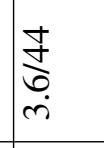 & $\underset{\substack{y \\
ָ}}{\stackrel{y}{i}}$ \\
\hline$\left|\begin{array}{c|c} \\
0 \\
\vdots \\
0 \\
0 \\
0\end{array}\right|$ & 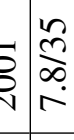 & $\frac{\stackrel{N}{+}}{\tilde{m}}$ & $\underset{\stackrel{?}{+}}{\stackrel{\sim}{+}}$ & 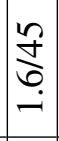 & $\begin{array}{l}\infty \\
\stackrel{\infty}{n} \\
\dot{r}\end{array}$ & $\begin{array}{l}0 \\
\stackrel{+}{n} \\
\\
i\end{array}$ & & $\frac{n}{n}$ & 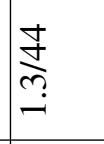 & $\frac{\hat{m}}{\sigma}$ & 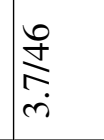 & 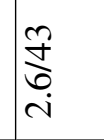 \\
\hline 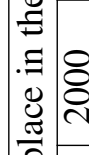 & 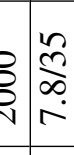 & 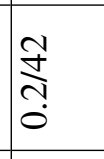 & 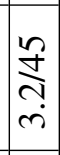 & 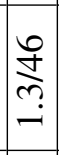 & 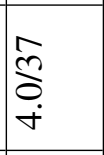 & \begin{tabular}{l}
$\stackrel{0}{+}$ \\
\multirow{+}{f}{} \\
i.
\end{tabular} & & $\frac{\infty}{m}$ & ふે & 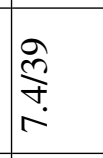 & 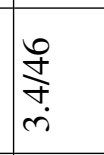 & $\underset{-}{\stackrel{f}{\sigma}}$ \\
\hline 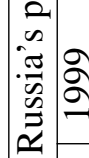 & 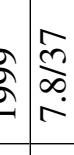 & $\stackrel{m}{\stackrel{n}{+}}$ & $\begin{array}{l}0 \\
\stackrel{+}{+} \\
\dot{i} \\
i\end{array}$ & \begin{tabular}{l}
0 \\
\multirow{2}{*}{} \\
\\
0
\end{tabular} & $\begin{array}{l}0 \\
\stackrel{n}{n} \\
i n\end{array}$ & & $\stackrel{0}{\stackrel{1}{0}}$ & હે & 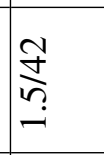 & సે & 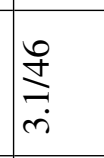 & 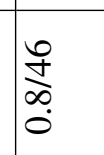 \\
\hline 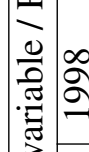 & 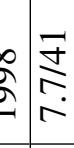 & 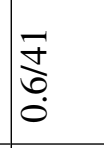 & & 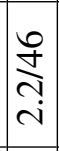 & $\begin{array}{l}\infty \\
\stackrel{\infty}{\infty} \\
\dot{m}\end{array}$ & & & 苂 & & Æે. & \begin{tabular}{l}
0 \\
\multirow{1}{0}{} \\
$\dot{m}$
\end{tabular} & $\underset{\stackrel{Y}{\&}}{\stackrel{\sim}{i}}$ \\
\hline 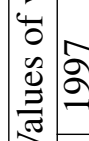 & $\hat{\alpha}$ & $\frac{\mathfrak{y}}{\tilde{y}}$ & & $\stackrel{0}{\stackrel{0}{+}}$ & 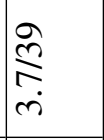 & & $\stackrel{\frac{n}{8}}{\frac{n}{-}}$ & $\stackrel{m}{ٍ}$ & & $\underset{\substack{+ \\
\text { mo } \\
0}}{ }$ & $\frac{0}{a}$ & $\frac{0}{0}$ \\
\hline รั & 20 & $\frac{\stackrel{y}{f}}{\stackrel{n}{0}}$ & & & & & 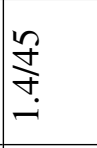 & $\begin{array}{l}m \\
\infty \\
\infty \\
\dot{m}\end{array}$ & & 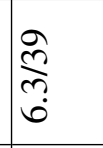 & & \\
\hline 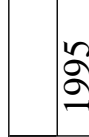 & $\delta_{\substack{\infty \\
\infty}}^{\infty}$ & & & & & & $\stackrel{0}{\stackrel{1}{0}}$ & $\stackrel{m}{\check{a}}$ & & $\begin{array}{l}\infty \\
\infty \\
\infty \\
\infty \\
\infty\end{array}$ & & \\
\hline 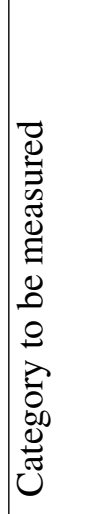 & 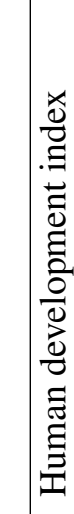 & 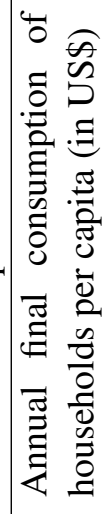 & 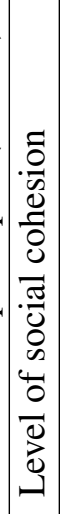 & 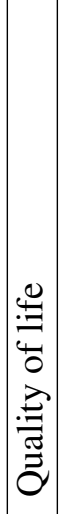 & 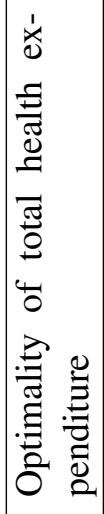 & 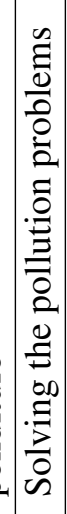 & 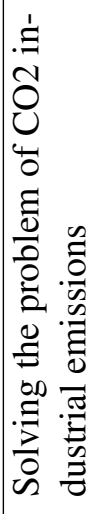 & 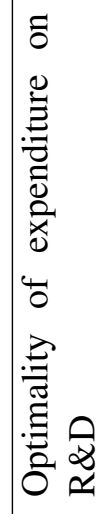 & 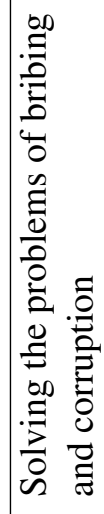 & 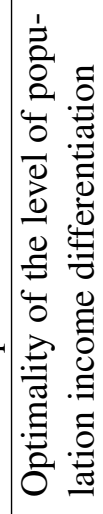 & 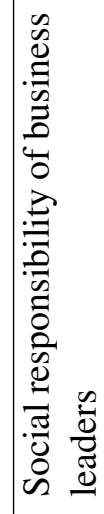 & 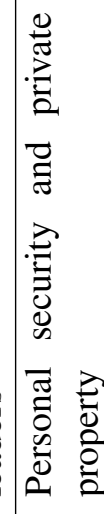 \\
\hline 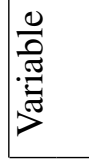 & $\underbrace{}_{i a s}$ & dי & $\frac{\sigma}{\sigma_{1}}$ & I্ম & $\underset{18}{\underset{18}{2}}$ & $\frac{\widehat{O}}{18}$ & $\underset{18}{\stackrel{\nexists}{18}}$ & $\frac{0}{180}$ & $\underset{18}{\underset{18}{E}}$ & 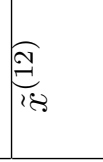 & $\underset{18}{\stackrel{20}{(28}}$ & $\underbrace{0}_{18}$ \\
\hline
\end{tabular}




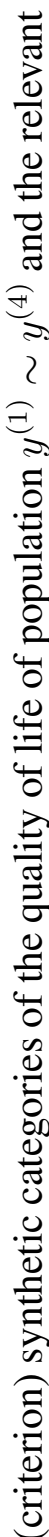

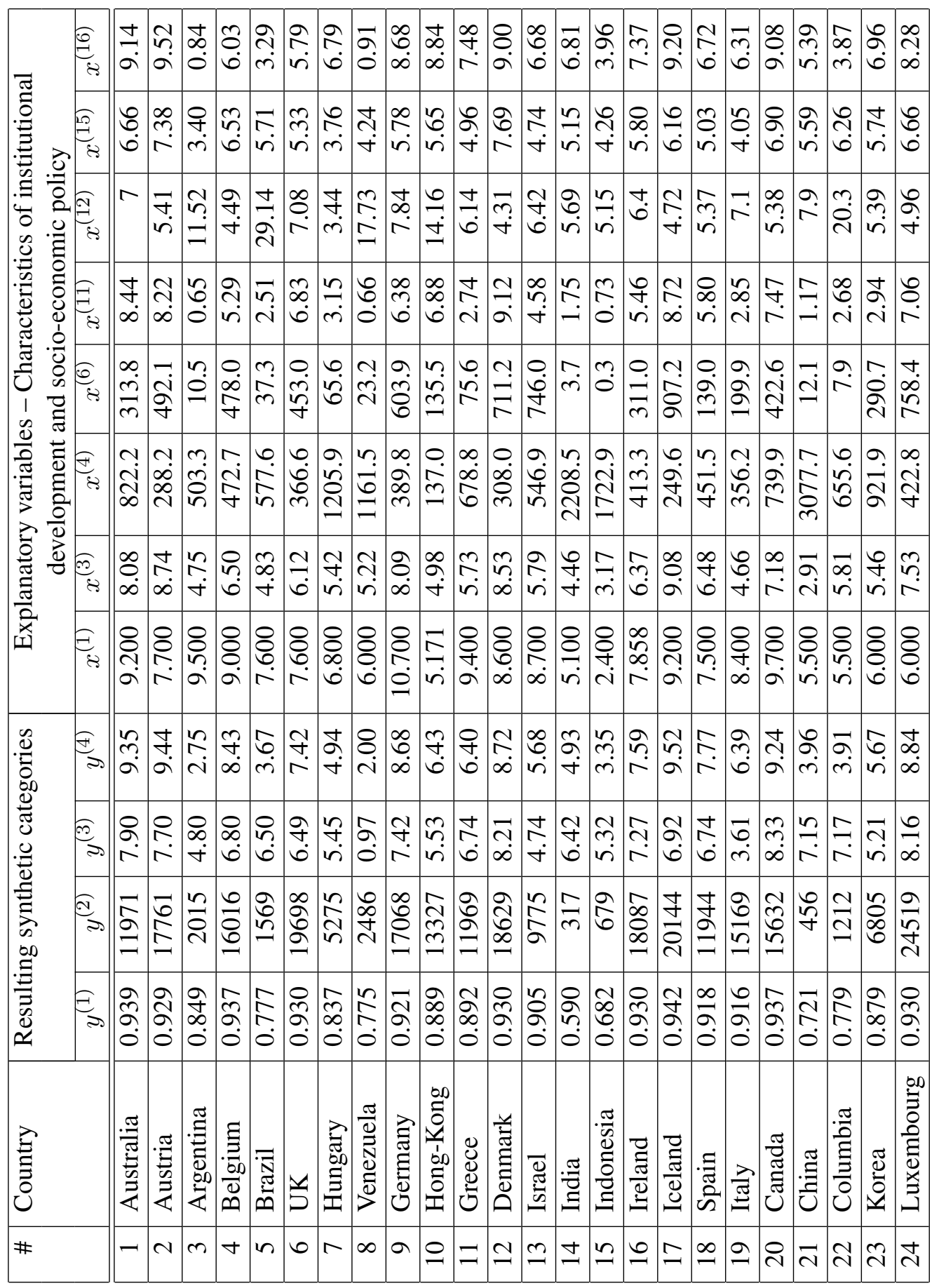

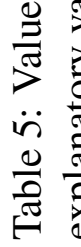




\begin{tabular}{|c|c|c|c|c|c|c|c|c|c|c|c|c|c|c|c|c|c|c|c|c|c|c|c|}
\hline \multirow{8}{*}{ 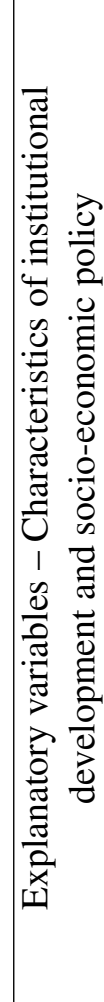 } & $\underset{\&}{0}$ & $\begin{array}{c}a \\
\dot{\gamma} \\
r\end{array}$ & $\frac{\mathbb{N}}{\stackrel{\sim}{*}}$ & & & $\begin{array}{l}\infty \\
\infty \\
\infty\end{array}$ & 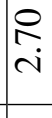 & & & $\frac{a}{a}$ & $\stackrel{2}{2}$ & $\stackrel{\overbrace{}}{\stackrel{2}{r}}$ & ণ্? & & $\bar{m}$ & $\frac{5}{9}$ & $\underset{r}{\stackrel{q}{r}}$ & 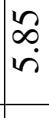 & $\stackrel{0}{\stackrel{0}{r}}$ & 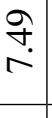 & {$\left[\begin{array}{l}\tilde{\lambda} \\
\tilde{a}\end{array}\right]$} & $\begin{array}{c}\hat{b} \\
\dot{m}\end{array}$ & \\
\hline & $\underset{\&}{\stackrel{2}{2}}$ & {$\left[\begin{array}{l}n \\
n \\
0\end{array}\right.$} & 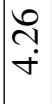 & 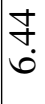 & గn & $\frac{n}{r}$ & $\stackrel{\mathcal{F}}{\stackrel{f}{*}}$ & $\stackrel{m}{\oplus}$ & 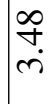 & & $\begin{array}{l}\infty \\
\infty \\
i\end{array}$ & ஸ্ & $\begin{array}{l}\text { के } \\
\text { in }\end{array}$ & & in & $\stackrel{\infty}{\stackrel{\infty}{0}}$ & సֶ. & 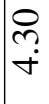 & $\widehat{\overbrace{}}$ & \begin{tabular}{c}
0 \\
\hdashline \\
$\therefore$
\end{tabular} & $\left|\begin{array}{l} \pm \\
\infty \\
\dot{n}\end{array}\right|$ & $\begin{array}{l}\infty \\
\infty \\
0 \\
0\end{array}$ & \\
\hline & $\overbrace{i}^{\mathbb{E}}$ & 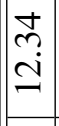 & 苛 & $\begin{array}{l}a \\
\dot{\sigma} \\
\text { in }\end{array}$ & 政 & $\begin{array}{l}\hat{b} \\
\dot{r}\end{array}$ & $\begin{array}{l}8 \\
\text { id }\end{array}$ & $\bar{a}$ & $\underset{\ominus}{\tilde{O}}$ & $a^{\infty}$ & $\begin{array}{l}\sigma \\
\infty\end{array}$ & लें & $\stackrel{1}{\infty}$ & $\varnothing$ & bे & $\underset{\sim}{\tilde{f}}$ & $\mid \begin{array}{l}\infty \\
n \\
n\end{array}$ & $\stackrel{g}{\stackrel{q}{r}}$ & $\mid \begin{array}{l}0 \\
0 \\
0\end{array}$ & $\begin{array}{l}\stackrel{\vartheta}{r} \\
\dot{r}\end{array}$ & $\left|\begin{array}{l} \pm \\
\infty \\
i \\
i\end{array}\right|$ & $\begin{array}{l}\vec{n} \\
\stackrel{n}{m} \\
m\end{array}$ & \\
\hline & $\underset{\&}{E}$ & $\left|\begin{array}{l}8 \\
\dot{\forall}\end{array}\right|$ & $\stackrel{\infty}{\infty}$ & $\stackrel{?}{\stackrel{0}{6}}$ & $\begin{array}{l}0 \\
\infty \\
\infty\end{array}$ & 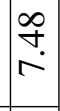 & 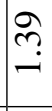 & $\begin{array}{l}8 \\
+\end{array}$ & $\stackrel{n}{\sim}$ & $\begin{array}{l}\text { in } \\
\infty\end{array}$ & రి & $\begin{array}{l}\stackrel{\otimes}{+} \\
\stackrel{+}{*}\end{array}$ & $\begin{array}{l}2 \\
\text { i }\end{array}$ & & $\stackrel{\overbrace{}}{\sim}$ & 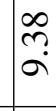 & $\frac{7}{6}$ & in & $\begin{array}{l}\infty \\
\infty \\
\dot{n}\end{array}$ & 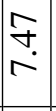 & 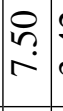 & $\begin{array}{l}\stackrel{\sim}{f} \\
\dot{r}\end{array}$ & \\
\hline & $\underset{s}{0}$ & {$\left[\begin{array}{r}n \\
\stackrel{\sim}{\sim}\end{array}\right.$} & הి & $\begin{array}{l}\stackrel{b}{n} \\
\stackrel{n}{f}\end{array}$ & 苋 & $\begin{array}{l}\vec{i} \\
\vec{\delta} \\
\delta\end{array}$ & $\hat{\dot{p}}$ & $\vec{\Xi}$ & $\hat{\grave{\lambda}}$ & $\begin{array}{l}\hat{\sim} \\
\tilde{\gamma} \\
\gamma\end{array}$ & नें & $\mid \begin{array}{c}1 \\
\infty \\
\infty \\
\sim\end{array}$ & is & & $\dot{0}$ & $\begin{array}{l}\sim \\
\infty \\
\infty \\
R\end{array}$ & $\begin{array}{l}0 \\
\hat{\tilde{N}} \\
\tilde{n}\end{array}$ & $\mid \begin{array}{l}n \\
\infty \\
\infty \\
\infty\end{array}$ & $\mid \begin{array}{l}n \\
\tilde{N}\end{array}$ & 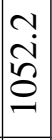 & $\mid \begin{array}{c}c \\
\infty \\
\infty \\
\infty\end{array}$ & & \\
\hline & & $\mid \begin{array}{l}a \\
\stackrel{a}{a} \\
\end{array}$ & 孚 & $\begin{array}{l}0 \\
\frac{\infty}{\gamma}\end{array}$ & $\begin{array}{l}0 \\
6 \\
n\end{array}$ & $\begin{array}{l}0 \\
\dot{d} \\
\dot{\sim}\end{array}$ & $\begin{array}{l}\hat{\infty} \\
\frac{\infty}{2}\end{array}$ & 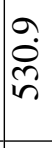 & 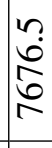 & $\begin{array}{l}\infty \\
i n \\
\dot{b}\end{array}$ & గָ. & $\underset{\equiv}{0}$ & $\stackrel{\overbrace{}}{\stackrel{\overbrace{}}{\Xi}}$ & $\sigma$ & $\underset{\substack{\infty \\
\infty}}{\stackrel{\infty}{\infty}}$ & $\begin{array}{l}\bar{\Sigma} \\
\text { శ }\end{array}$ & 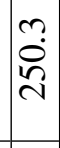 & $\begin{array}{l}\stackrel{0}{i} \\
\stackrel{N}{\stackrel{N}{c}}\end{array}$ & $\mid \begin{array}{l}m \\
\infty \\
\infty \\
\infty\end{array}$ & $\frac{\infty}{a}$ & $\begin{array}{l}\stackrel{+}{+} \\
\stackrel{\sim}{n}\end{array}$ & 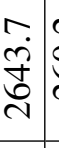 & \\
\hline & $\underset{\&}{\infty}$ & స్ & $\begin{array}{l}\infty \\
\infty \\
\dot{n}\end{array}$ & $\frac{0}{\pi}$ & $\widehat{\sigma}$ & $\begin{array}{l}\infty \\
\infty \\
\infty \\
\infty\end{array}$ & $\stackrel{\Re}{\stackrel{\vartheta}{r}}$ & 每 & $\begin{array}{l}\infty \\
\dot{+}\end{array}$ & $\underset{\infty}{\stackrel{m}{\infty}}$ & $\begin{array}{l}\varkappa \\
\text { ֶु. }\end{array}$ & . & $\frac{f}{n}$ & $\stackrel{\sim}{\sim}$ & $\frac{d}{i}$ & $\begin{array}{l}6 \\
\infty \\
\infty\end{array}$ & $\begin{array}{l}0 \\
0 \\
0\end{array}$ & $\begin{array}{l}2 \\
\tilde{n} \\
n \\
n\end{array}$ & $\begin{array}{c}1 \\
6 \\
i r\end{array}$ & $\begin{array}{c}8 \\
\infty \\
\infty\end{array}$ & $\underset{\infty}{8}$ & $\begin{array}{l}\infty \\
\infty \\
\dot{1} \\
1\end{array}$ & \\
\hline & $\underbrace{}_{\infty}$ & $\left|\begin{array}{l}0 \\
\infty \\
\infty \\
r i d\end{array}\right|$ & @ & $\begin{array}{l}\mathscr{\infty} \\
\wp \\
\infty\end{array}$ & $\frac{8}{\infty}$ & $\begin{array}{l}8 \\
\varnothing \\
\infty \\
\infty\end{array}$ & ס̊ & ڤ్రి & 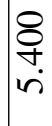 & 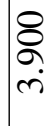 & $\begin{array}{l}8 \\
\S \\
\end{array}$ & $\frac{N}{\sigma}$ & $\begin{array}{l}\stackrel{8}{m} \\
\dot{m}\end{array}$ & 1̊ & $\begin{array}{l}\text { ঠे } \\
\text { m. }\end{array}$ & $\underset{r}{8}$ & $\begin{array}{l}8 \\
0 \\
n \\
a\end{array}$ & 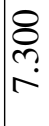 & 要 & $\mid \begin{array}{l}2 \\
r \\
r \\
r\end{array}$ & $\begin{array}{l}8 \\
\stackrel{0}{\beth} \\
=\end{array}$ & & \\
\hline \multirow{4}{*}{ 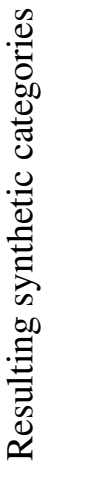 } & $\mathbb{F}_{\rightarrow}$ & $\begin{array}{l}\vec{J} \\
r \\
r\end{array}$ & $\stackrel{\vartheta}{\dot{\gamma}}$ & 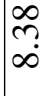 & $\begin{array}{l}\infty \\
\infty \\
\infty\end{array}$ & $\bar{a}$ & $\stackrel{I}{\check{m}}$ & $\frac{7}{6}$ & $\begin{array}{c}\hat{\delta} \\
\dot{r}\end{array}$ & $\underset{\infty}{ \pm}$ & $\underset{\infty}{\bar{\infty}}$ & $\hat{\sigma}$ & $\stackrel{?}{\stackrel{n}{i n}}$ & $\stackrel{ }{N}$ & $\stackrel{f}{\text { f }}$ & $\begin{array}{l}\infty \\
\infty \\
\infty\end{array}$ & $\mid \begin{array}{l}0 \\
\infty \\
\infty\end{array}$ & $\begin{array}{l}\text { त̂ } \\
\text { b }\end{array}$ & $\mid \begin{array}{c}\tilde{f} \\
\dot{0}\end{array}$ & $\begin{array}{l}\hat{\lambda} \\
\infty\end{array}$ & $\begin{array}{l}\tilde{n} \\
\tilde{\sigma}\end{array}$ & $\begin{array}{c}\stackrel{\infty}{+} \\
\dot{+}\end{array}$ & ס \\
\hline & कृ & $\mid \begin{array}{l}\mathscr{\sigma} \\
\dot{\infty} \\
\infty\end{array}$ & $\frac{\infty}{i n}$ & & $\frac{N}{r}$ & $\frac{n}{\infty}$ & $\begin{array}{l}\infty \\
\infty \\
\sim \\
\sim\end{array}$ & กี & $\underset{+}{\mathscr{8}}$ & 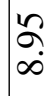 & it & $\tilde{\sigma}$ & लે & $\stackrel{\infty}{\infty}$ & $\stackrel{\infty}{\stackrel{一}{+}}$ & $\underset{\infty}{\stackrel{\vartheta}{+}}$ & $\begin{array}{l}2 \\
0 \\
0\end{array}$ & \begin{tabular}{l}
$\infty$ \\
$\infty$ \\
\hdashline
\end{tabular} & $\begin{array}{l}\sigma \\
\sigma \\
r\end{array}$ & $\bar{r}$ & $\left|\begin{array}{l}n \\
0 \\
r\end{array}\right|$ & \begin{tabular}{l}
\multirow{n}{*}{} \\
6
\end{tabular} & \\
\hline & 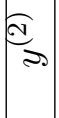 & 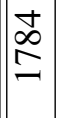 & ஓ্ণি & $\begin{array}{l}n \\
n \\
n \\
n\end{array}$ & 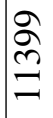 & $\begin{array}{l}\vec{n} \\
\overrightarrow{\tilde{N}}\end{array}$ & $\frac{\hat{a}}{m}$ & $\frac{R}{2}$ & 吾 & $\frac{n}{a}$ & 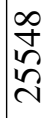 & 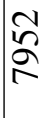 & $\stackrel{\infty}{\beth}$ & & $\frac{2}{6}$ & $\mid \begin{array}{l}n \\
\tilde{\hat{d}} \\
\underline{\sigma}\end{array}$ & $\begin{array}{l}\infty \\
\mathbb{1} \\
\underline{0}\end{array}$ & $\underset{f}{g}$ & $\underset{\stackrel{N}{\mathcal{O}}}{\stackrel{\sim}{\sim}}$ & $\begin{array}{l}n \\
\infty \\
\tilde{\sigma} \\
-\end{array}$ & 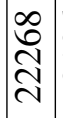 & & \\
\hline & $\mathbb{F}_{\lambda}$ & $\mid \begin{array}{l}2 \\
\therefore \\
0 \\
0\end{array}$ & $\mid \begin{array}{l}8 \\
\infty \\
0 \\
0\end{array}$ & $\underset{\substack{\infty \\
0}}{0}$ & $\frac{1}{a}$ & 声 & 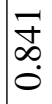 & $\begin{array}{l}0 \\
\infty \\
0 \\
0\end{array}$ & $\frac{2}{\hat{2}}$ & $\mid \begin{array}{l}0 \\
\infty \\
\infty \\
0 \\
0\end{array}$ & $\hat{\widehat{\jmath}}$ & 免 & \begin{tabular}{l}
$\infty$ \\
\multirow{2}{0}{} \\
$\stackrel{0}{0}$
\end{tabular} & & $\frac{\tilde{n}}{\tilde{o}}$ & ô & 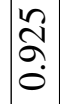 & $\begin{array}{l}\bar{\sigma} \\
\infty \\
0\end{array}$ & $\begin{array}{l}\bar{m} \\
\infty \\
0\end{array}$ & Fे & $\begin{array}{l}\tilde{\sigma} \\
\hat{\sigma}\end{array}$ & $\begin{array}{l}\begin{array}{l}0 \\
0 \\
0 \\
0 \\
0\end{array} \\
\end{array}$ & \\
\hline $\begin{array}{l}\stackrel{\Xi}{\Xi} \\
\stackrel{\Xi}{0} \\
\text { Un }\end{array}$ & & 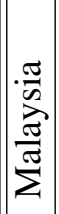 & : & 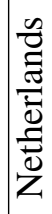 & $\begin{array}{l}\tilde{U} \\
N \\
z \\
0 \\
\text { Z }\end{array}$ & 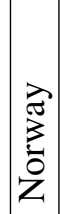 & $\frac{Z}{\tilde{\Xi}}$ & 苂 & 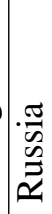 & & & 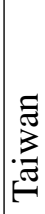 & స్ & & $\frac{\bar{z}}{2}$ & $\frac{\vec{\Xi}}{\stackrel{\Xi}{\Xi}}$ & 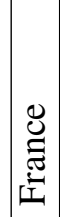 & נֶ. & $\frac{\stackrel{\theta}{\Xi}}{\bar{U}}$ & 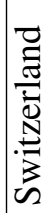 & & & \\
\hline & & & & & & & & & & & & & & & & & 우 & & & $\mathrm{V}$ & $\forall$ & & \\
\hline
\end{tabular}

